\title{
Criteria Evaluation in the Formation of Student Competencies
}

\author{
Koshanova Gulyash ${ }^{1}$ Mamayeva Venera ${ }^{2}$, Kulzhagarova Bazarkul ${ }^{3}$, \\ Shuakbayeva Rakhat ${ }^{4}$ and Saparbayeva Sholpan ${ }^{4}$
}

${ }^{1}$ Department of Pedagogical Sciences, Caspian State University of Technology and Engineering Sh. Essenov, Kazakhstan

${ }^{2}$ Department of Natural Sciences, KazNU Al-Farabi, Kazakhstan

${ }^{3}$ Department of Physical and Mathematical Sciences, Caspian State University of Technology and Engineering Sh. Essenov, Kazakhstan

${ }^{4}$ Caspian State University of Technology and Engineering Sh. Essenov, Kazakhstan

\begin{abstract}
Pedagogical education in Kazakhstan has reached a new level of development. Changes occurring in the value, target, functional and other spheres of modern education require adequate identification and scientific and pedagogical comprehension. The essence of these changes, affecting both individual national structures and the world community as a whole, can be designated by the term 'integration'. Confrontation is replaced by an association that implies a complex interaction between interests of individual subjects of integration and requires a qualitatively new level of management and regulation of such interactions. The dynamics of change in various areas determines the shifts in the geopolitical, economic, social and other conditions of human activity.

The objective of this article was to examine evaluation of training in higher education as an integral part of teacher daily work. A questionnaire was administered to a group of teachers, who responded to several items related to these six dimensions: discipline, characteristics of the course, evaluation tools, evaluation practices, communication between teacher and student, and involvement of teachers in improving learning assessment.
\end{abstract}

Keywords: Education, criteria, assessment, technology, competence, formation, model.

\section{INTRODUCTION}

Assessment describes a particular style of testing, but more importantly has come to be associated with an alternative way of thinking about assessment. Most succinctly, assessment involves embedding interaction within the assessment and observing and recording the learner's response and ability to profit from this interaction. This research aims to discuss the issues of criteria evaluation in competence formation. There are numerous models of assessment that vary in terms of the degree of structure and the timing of the intervention, as well as the content of the intervention procedure. The greatest distinction between assessment and conventional testing, or what is frequently referred to in the literature as static assessment, can be seen in the shift from product to process orientation regarding testing. This distinction has numerous implications not only with regard to actual assessment techniques but also with respect to the types of question asked and solution formulated with regard to low cognitive functioning and/or poor academic performance. Assessment is an interactive process between the assessor and the assessed. It

Address correspondence to this article at the Kazakh State National University of al-Farabi, Almaty, Kazakhstan; Tel: +77073851878;

E-mail: zhanat_2006@mail.ru differs from conventional psychometric assessments in that no 'normative score' such as an Intelligence Quotient is computed. It differs also in that mediation is an essential part of the process. Tasks are given to the assessed, with the focus primarily on how the tasks are tackled. This makes it possible to pin-point necessary areas of cognitive development. At different stages for different tasks in the overall process, mediation is given in the cognitive functions and strategies necessary to master the tasks. Assessment embeds interaction within the framework of a test-intervene-retest approach to psycho educational assessment [1].

One of the important conceptual provisions for updating the content of education in the 21st century is the competence approach. The use of such an approach promotes the displacement of traditional cognitive orientations of education, leading to a new vision of the very content of education, its methods and technologies. As the basic units of renewal are the concepts of competence and competence, these become integrative indicators of the evaluation of the quality of education.

Modernisation of the domestic education assumes the following: formation of key competencies of students, ensuring their functional literacy, responsibility in the choice of educational trajectories 
and self-development. In pedagogical literature ${ }^{1}$, when considering the problem of the quality of education, there is a need to move from the paradigm of assessing the achievements of students in terms of knowledge, skills and skills to assessing the level of their key competencies. The educational system faces the problem of developing graduates' readiness and ability to adapt to new socio-cultural requirements, the need to independently find answers to the questions posed by life,; the ability to assess the consequences of their actions and to be ready to bear responsibility. This can be achieved by directing the educational process in schools to self-study and self-development as the basis for the formation of educational and cognitive competence of students and their readiness and ability to self-educate throughout life [2].

In accordance with this, the choice of assessment technology based on the competence approach must be considered, taking into account the individual characteristics of the students and developing a diverse educational environment. The latter includes all the diversity of modern technologies and individual educational trajectories. Variability is aimed at maximum individualisation and accessibility of education, the flexibility of the educational process based on the interrelated work of its participants in the implementation of goals and the choice of content within the national framework [3].

It is natural that in connection with the emergence of an updated educational paradigm, new educational standards based on a competence approach, the focus of the professional pedagogical community and participants of the educational process was the problem of the formation of a reliable, transparent, valid and technological system with a systemic, interdisciplinary character for assessing the learning achievements of students. However, up to the present, there has not been a single universal system of evaluation that meets the requirements of our changed society and educational space as a whole.

In the modern system of training students, the priority goal of education is the development of individuals who are ready for effective interaction with the surrounding world through self-education and selfdevelopment [4]. To achieve "educational independence, monitoring and evaluation, the independence of the child, that is, readiness and the ability to monitor and evaluate one's activity, establish

${ }^{1}$ Bobrova, A. G. Bermus, A.A. Rean, A.B. Khutorskaya and others. and eliminate the causes of the difficulties that arise, are of particular importance. To form these skills, is it necessary to make significant changes in the control and evaluation? activity in the university, revise its goals, content and technology.

\section{METHODS}

The research has been carried out at the Faculty of psychology, at Kazakh National University. A total number of 150 students all in the BA level.

Time of the surveying is 90 minutes. Survey method was used in the study. The subjects were administered a questionnaire in which they were asked to answer questions related to education system. Items used in the questionnaire were prepared according to the related literature and interview results conducted with some teachers. Descriptive and inferential analyses were conducted to get a deeper insight into the research questions.

The method used in this research entailed theoretical analysis of philosophical, psychological and pedagogical works and methodical publications as well as pedagogical experience on the research problem. It also involved analysis of normative documents on the research topic, state educational standards of basic general education, training programmes, domestic and foreign educational and methodical complexes. The method of modelling and empirical methods used were pedagogical observation, interviews, interviewing, questioning and testing. In addition, interpretation methods of research such as analysis, comparison, generalisation of theoretical studies, practical experience, empirical material, synthesis and systematisation of empirical material were also used. A pedagogical experiment based on ascertaining, forming and control experiments, was undertaken to check the effectiveness of the proposed technology, and the processing of results was done using statistical methods.

The methodological bases of the study are: the provisions of the system approach in pedagogy and education; the theoretical and practical aspects of pedagogical modelling; the provisions of dialectics on the universal connection and interdependence of phenomena; and, the provisions of the philosophy of education on the socio-cultural nature of pedagogical processes. The experiment was conducted in educational institutions of the city of Aktau and secondyear students were invited to take part in the experimental work. 
Table 1: Students Think that Evaluation Assists in Competence Formation

\begin{tabular}{|c|c|c|c|c|c|}
\hline Strongly agree & Agree & Not sure & Disagree & Strongly disagree & Mean \\
\hline \hline $22 \%$ & $44 \%$ & $18 \%$ & $16 \%$ & $0 \%$ & 2.28 \\
\hline
\end{tabular}

In accordance with the stated goal, the proposed hypothesis and the tasks established for the implementation of the research was carried out in two stages from 2017 to 2018 . Reliability and validity of the research results was provided by reliance on scientific methodology, various sources of philosophical, pedagogical, psychological, methodological information; multi-level analysis of basic concepts; complex, purposeful application of complementary research methods, adequate to the goals, subject, tasks and logic of research; a combination of theoretical analysis of the problem and the practical introduction of general educational institutions in the educational process, positive results (qualitative and quantitative) of experimental and experimental work; a representative sample, the correct processing of the data obtained, the statistical significance of the data obtained, which ensured the validity and reliability of the results obtained, the possibility of introducing the main provisions and results of the study into the practice of the work of educational institutions and the possibility of using the developed model and technology of criterial evaluation in various educational systems [5].

\section{RESULTS}

To answer the questions above, students' reported responses on the questionnaire discussed accordingly and illustrated in tables. As having mentioned before at the methodology part, the given research conducted in evaluation used a questionnaire with 22 items.

However, it was decided that there are no necessity to represent all of the figures on every item, so the main significant ones are shown in this paper, for researcher with arising interest in the problem of evaluation we ask to contact for detailed data.

The table shows that evaluation is a technique preferred by students when formation of competence in classroom. Sixty-six of students reporting their agreement on it for this function, including $22 \%$ who strongly agreed.

However, only $10 \%$ expressed their disagreement, and $16 \%$ were not sure whether they use or not when discussing. With $66 \%$ of students would prefer to keep sensitive issues confidential or would not like to share what think does personal with the international students fear that their image would be encroached.

\section{DISCUSSION}

The problem of appraisal activity is one of the most urgent problems both in pedagogical theory and in pedagogical practice. The existing assessment system was formed within the knowledge paradigm of education and therefore, reflects the result of mastering knowledge, and not the process of their assimilation, which does not fully meet the modern requirements of the competence approach.

The assessment process is a constant component of the educational process and is also subject to development. The contradictory nature of the mark was noted by Ya. A. Comenius and K. D. Ushinsky. Describing the shortcomings of the modern assessment system, they emphasised that the mark should not suppress the mental activity of students. During the last 20 years, the issues in education related to the evaluation of students' learning achievements $^{2}$. The necessity of creating a universal system of assessment that meets all the requirements of modern society and the needs of the individual was proven $^{3}$.

A significant contribution to the development of the theory of evaluation was made by researchers who defined evaluation as the result of educational activity, noting the systematic nature of the assessment process, and suggesting that evaluation be performed based on a chosen standard. Many scientists considered the issue of evaluation from a social standpoint. No less significant, in the opinion of scientists, such problems as a competent organisationevaluation process in order to form educational and cognitive motivation and incentives for students, educational achievements. For the present study, it is of interest to propose that the evaluation criterion be regarded as a standard, an indicator of the level of

${ }^{2}$ Sh. A. Amonashvili, B.J. Bespalko, VV Davydov, AA Rean, NM Skatkin, DV Chernilevsky, DB El'konin and others.

${ }^{3}$ Sh.A. Amonashvili, BG Ananiev, AB Vorontsov, IV Gladkaya, AA Rean, DB El'konin and etc. 
possession of the teaching material, which has the value of an incentive for improving the learning achievements of students.

The literature shows that in the past few years, no work has been devoted to the problem of the formation of competence through criterial evaluation that is, the competence of the learner, formed by a personconscious experience in the successful implementation of educational and cognitive activities at the interdisciplinary level. Despite the versatility of the studies carried out and their unquestionable theoretical and applied significance, the works devoted to the problem of evaluative activity of students do not exhaust the problem of the formation of educational and cognitive competence, and these matters have not been fully addressed. In this regard, it is advisable to consider the definition of pedagogical grounds for the formation and development of educational and cognitive competence of students using the technology of criterial evaluation of their academic achievements as a modern scientific trend [6].

The main problem in assessment is the subjectivism of the marking. The issue of the lack of clear criteria in the choice of a mark and the absence of constructive information in the mark of what is the cause for the low or high score, as well as the difficulty of ranking results by means of scoring are all matters that require consensus. The problem of assessing the learning achievements of students can be solved by forming a criterial assessment of the results of mastering the basic educational programmes by students that are made known to students at the initial stage of training [7]. The literature on this issue, based on research, domestic and foreign experience and observation of the educational process identifies a number of existing contradictions [8]. Thus, the urgency of developing a technology for criterion estimation is determined by the need to resolve these contradictions. All that has been said has determined the problem as uncovered by research i.e.: What is the technology of criterial evaluation of students, contributing to the formation of the competence of students?

The urgency of this problem, its lack of theoretical and practical elaboration, was the basis for defining the topic of this research. The aim of this research was to develop and practically test the criterial evaluation technology that contributes to the formation of competence in students. This research presents a model of the technology of criterial evaluation in the educational process, taking into account the social order of society and the needs of the learner's personality and including purpose, principles, evaluation policy and organisational and pedagogical conditions. The proposed model is implemented in practice as a two-part system of measures of an organisational and content nature aimed at forming the competence of students.

\section{CONCLUSION}

Evaluation is essential in teaching and learning. The reform of the university system took into account the evaluation system of learning by adopting continuous controls. However, it ignored other parameters that must necessarily accompany them. While the effectiveness of the evaluation of learning depends on the conditions of learning, it can yet be designed if there is a good and structured learning environment based on communication and cooperation between the various stakeholders, orientated towards an effective evaluation system and not only relying on compliance with educational prefectures that are in force and that require continuous improvement in the observations recorded during their implementation application.

Recently, researchers have shown interest in the problems such as the role of the technology of criterial evaluation in the formation of competency of trainees with an interdisciplinary character, the identification of the organisational and pedagogical foundations of criterial estimation technology and the development of a model for the practical implementation of this technology. The emergence of a variety of approaches to evaluation contributed to the establishment of a wellfounded general pedagogical concept of a competence approach i.e. person-orientated, developmental learning. This predetermined the current trends in the development of the evaluation system and necessitated the emergence of a technology of criterial evaluation, which consisted in comparing the individual achievements of students against certain criteria based on a competence approach and having an interdisciplinary nature.

In the practice of forming competence through criterial evaluation, a model of criterial evaluation technology was implemented in this research, including the purpose, principles, evaluation policy of the educational process, together with a set of technologies for organising criterial evaluation, organisational and pedagogical conditions and an effective component of the application of criterion estimation technology. The effectiveness of the 
content, organisational foundations and model of this technology was confirmed by the results of experimental research, which made it possible to identify the quantitative and qualitative parameters of the effectiveness of criterial evaluation as a technology for the formation of educational and cognitive competence of students.

The research revealed pedagogical principles based on the regularities of the relationship between criteriality and discretion and forming and ascertaining assessment, awareness and diagnostic tests. These are used to regulate evaluation parameters. However, conducted research does not pretend to be exhaustive; more work is needed in the area of introducing and using criterion estimation technology, which has an interdisciplinary character. Future research could consider the impact of criterial evaluation technology on the formation of key competencies of students.
[2]

Pelletier G. L'évaluation des apprentissages à l'université de Montréal et dans ses écoles affiliées. Montréal groupe de Recherche Interdisciplinaire en Pédagogie Universitaire 1997.

[3] Gilles J-L, Detroz P, Blais J-G. An international online survey of the practices and perceptions of education professors with respect to the assessment of learning in the classroom. Assessment and Evaluation in Higher Education 2011; 36(6): 719-733. https://doi.org/10.1080/02602938.2010.484880

[4] Romainville M. l'évaluation des acquis des étudiants dans l'enseignement universitaire 2002.

[5] Feuerstein R. Dynamic assessment of retarded performers: The learning potential, assessment device, theory, instruments and techniques. Baltimore: University Park Press Publishing 1979.

[6] El Melhaoui S, Kaaouachi A, Ouafae B. les déterminants des pratiques d'évaluation des apprentissages à l'université Mohammed Premier, colloque national L'enseignement supérieur au Maroc: quel enseignement pour quelle efficacité? Rabat 12 décembre 2012.

[7] Haywood CH. Dynamic assessment in practice: Clinical and educational applications. Cambridge University Press 2006.

[8] Birzea C. Educational reform and power struggles in Romania. Journal of Education 1996; 31. Brian K., 2005.

\section{REFERENCES}

[1] Blais JG, Laurier M, Van der Maren JM, Gervais C, Lévesque M. Pour un enseignement efficace: l'approche par competences. Abderrahim Harouchi.

Received on 06-08-2018

\section{DOI: https://doi.org/10.6000/2292-2598.2018.06.03.11}

(C) 2018 Gulyash et al.; Licensee Lifescience Global.

This is an open access article licensed under the terms of the Creative Commons Attribution Non-Commercial License (http://creativecommons.org/licenses/by-nc/3.0/) which permits unrestricted, non-commercial use, distribution and reproduction in any medium, provided the work is properly cited. 